\title{
A Review Note on Shifting Cultivation in Northeast India amidst Changing Perceptions
}

Ratna Bhuyan

\begin{abstract}
Historically, shifting cultivation has been traced back to the neolithic period. It has undergone transitions from being a subsistence agriculture to small surpluses. Despite the global changes intruding into the socio-economic sphere of the tribal communities across Northeastern region of India, shifting cultivation continues to play an important role in providing livelihoods and food security to the rural tribal households. It seems that shifting cultivation is closely tied to the cultural identity of the tribal people. Therefore, its importance lies beyond mere economic concerns. Though with government interventions and under innovative shifting cultivation, the farmers in the region have switched to newer methods of cultivation, shifting cultivation continues parallel to sedentary cultivation accommodating at the same time the value system and needs of the tribal society. Concurrently, the Jhumias - shifting cultivators are constantly incorporating new measures into shifting cultivation to make it ecologically less destructive. Amidst changing perceptions on shifting cultivation practices, the paper tries to analyse the continuance of shifting cultivation in the region.
\end{abstract}

Keywords: Northeast India, shifting cultivation, sustainable alternatives to jhum, tribal communities.

\section{Introduction of Shifting Cultivation in Northeast India}

The history of shifting cultivation in the Northeastern Region of India is as old as human civilisation in the region. It is a primitive practice of cultivation across the hilly terrains of the region (Borthakur, 1992). The people involved in such cultivation are known as Jhumias across the region. The practice of shifting cultivation in the region since time immemorial has involved clearing of forest cover or slopes of hills, drying and burning them before onset of the monsoons and cropping on the cleared plots thereafter. During the post harvest period, the land is left fallow for vegetative regeneration until the plot becomes reusable for cultivation in next cycles. Meanwhile, a similar process is repeated in a new plot designated for jhum cultivation in the following year. It is worth mentioning here that the patches of land identified for shifting cultivation are not selected in any given order or sequence leaving a room for choice. It is found that the jhum cultivators who often migrate do not follow the cyclical methods of cultivation on a given plot. The plots are mostly identified based on ease of clearing the vegetation and soil fertility levels (Siddiqui \& Chohan, 2015).

The period of successive cropping and fallowing differs from region to region. In the past, the gestation period or jhum cycles in the region were recorded to be long, and ranged from 20-30 years. However, with increase of population pressure on land, the jhum cycles have been reduced progressively to five to six years or even less. This reduction in jhum cycles in the region, is not only causing poor economic yield due to degradation of soil ecology but also is identified with the sense of insecurity experienced by the tribal communities with a secured livelihood.

The period of sequential cropping also varies from tribe to tribe. In Arunachal Pradesh, a shifting cultivation plot once cleared is generally cultivated for two years leading to clearing of a new plot as the old one is abandoned. It is found that with the exception of the Idu-Mishmi in Lohit district and Sherdukpens in the Bomdila division of the West Kameng district in Arunachal Pradesh, Lotha, Rengma and Sema in Nagaland and Lushai in Mizoram, most of the tribes of the region cultivate the shifting cultivation plots for one year only. A rapid depletion of the soil is the reason for the short period of cultivation. The fallow period varies between eight to ten years. For the Aos, Khasis, Mikirs, Jaintias, Garos, Semas and Hmars, the fallow period is found to be even less than eight years. For the tribal societies with shorter jhum cycles, it becomes difficult to meet their household food nutrients with soil depletion and degradation.

Contrary to drastic reduction of jhum cycles in the region, the Adis of East and West Siang districts of Arunachal Pradesh and the Tangkhuls of Ukhrul district in Manipur are managing the ecosystem of shifting cultivation effectively. With a rich traditional ecological knowledge 
base, the Adis of the Siang districts have been maintaining well-defined Patat system where they maintain a fallow period of 14-35 years. The land of the village is divided into a number of blocks or patches locally called Patat with a specific name to each Patat. These blocks are then cultivated as per the shifting cultivation cycles. This entire process is guided by age-old traditional system involving various customary practices. It is the local level institutions who decide the Patat system. The clear division in the use of blocks for shifting cultivation helps the farmer in planning the patches for cultivation not only in the current year but also in future (Dolo \& Sundriyal, 2003). Since it is believed that the land under shifting cultivation is owned by the tribal community, it has a control over the resource use pattern. The individual infact, is allowed to cultivate the land for livelihood with a promise that he would observe the customary rules for conservation of the biological resources for future use. The rules and functioning of such traditional institutions are based on locally acceptable cultural values and are functional within each community, including the management of natural resources (Tripathi \& Barik, 2003).

During the 50 s of the last century, the jhum cycles were maintained at least upto 30 years by the tribes practising shifting cultivation but the cycles declined to three to seven years in the late $90 \mathrm{~s}$. The shortening of jhum cycles not only interjects the ecological balance of the cultivation practices but also adversely affects the entire fragile ecosystem. Thus, the ever shortening jhum cycles stand as a major challenge in the new millennium for the policy makers, academicians, researchers and the farming communities of the region.

The present paper is an attempt to review the practice of shifting cultivation in Northeastern region as an economic activity in the light of the changing perceptions on shifting cultivation in the region. The paper mostly reviews the secondary literature hitherto available on shifting cultivation in the region and synthesizes the implications with respect to the changing perceptions during the last three decades (1991-2019).

\section{Shifting Cultivation in Northeast India : The Merging Cultural Identities}

Shifting cultivation, though a rudimentary technique of land and forest resource utilisation, represents an intricate relationship between ecology, economy and society (Kerkhoff \& Sharma, 2006; Priyadarshni, 1995). Shifting cultivation in Northeast India is identified as a way of life for the societies practising it. In fact, it is found that the jhum fields surrounded by forests and nature offer two alternative sources of livelihoods to the population practising shifting cultivation. In case, the jhum crops are not good or fail due to external vulnerabilities like fire and landslides, the surrounding forest resources support the shifting cultivators by augmenting their food supplies. Moreover, these shifting cultivators, who practise piggery and keep swine, use vegetable wastes and inferior grains from the shifting cultivation fields as their feed.
Shifting cultivation is recognised as a catalytic force for community life across the Northeast India. The social organisation of the tribes living in the hills in the region is mostly built around community ownership, participation and responsibility. In the hilly tracts of the region comprising of the states of Arunachal Pradesh, Assam, Manipur, Meghalaya, Mizoram, Nagaland, Sikkim and Tripura, shifting cultivation continues to be a dominant economic activity. Therefore, in Northeast India, shifting cultivation is considered as a primary means of economic mainstay with exception to the plains of Assam, Tripura and valley areas of Manipur.

The usual process in shifting cultivation followed in the states of the region is the selection of a plot on or near the hillside or jungle. Carried out by village elders or clan leaders, this selection of the plot based on traditional knowledge of its fertility is usually done in the months of December and January. On most occasions, the community as a whole is collectively responsible for clearing of the selected jhum plots, while still in others, the cutting of trees and shrubs is made by the individual family to whom the plot is allotted.

On the day of sowing which is a ceremonial day for the whole village, it is interesting to observe that the males members of each family on reaching the jhum field in the morning engage themselves in preparing the digging sticks. The seeds are sown either by way of broadcast or dibbling. The dibbling and planting of seeds is an exclusive job of the females. While dibbling the seeds, the woman walk over the field with a digging stick or billhook in hand, make a hole in the ground, sow a few seeds and cover it over with earth by pressing it down with her toe (Chandel, 2017; Husain, 1995; Priyadarshni, 1995). The male members broadcast seeds of crops like millets and small millets, whereas crops like maize, pulses, cotton, sesame and vegetables are dibbled by females.

Most interestingly, before sowing starts, evil spirits and Gods and Goddesses are worshipped and sacrifices are made for a good crop and prosperity of the family. In the interior parts of the Garo and Khasi hills of Meghalaya, it is believed that if the throat of a cock is half cut and left walking in the field, and in the process, it dies lying on its right, the field will bring a bumper crop and prosperity to the family and vice versa (Priyadarshni, 1995). However, sacrifices before sowing is no more a common practice in the region. Many shifting cultivators in the region practise the custom of constructing a hut in the shifting cultivation field to guard it.

So far as the cropping pattern goes, the shifting cultivators in the region have been found to have adopted mixed cropping with respect to growing different crops. But it varies from tribe to tribe within the region. In mixed cropping, soil exhausting crops like rice, maize, millets and cotton are grown along with the soil enriching crops like legumes. Since the soil exhausting crops and soil enriching crops have different harvest periods, these crops supply food to the tribal communities almost throughout the year. Even when the fields are abandoned for the next cycle, intermittently, they provide residual crops to the farmers, 
thereby taking care of the nutritional aspect of the tribal communities. The shifting cultivators across Northeast India are mostly found to grow food grains and vegetables, and on rare occasions, some cash crops are also grown. Among food grains, the coarse varieties of rice, maize, job tears and small millets are the principal crops grown. Ginger, turmeric, cabbage, linseed, rapeseeds, sesame, oranges, pineapple and jute are the important cash crops grown in the shifting cultivation fields. Among vegetables, soya-bean, potato, pumpkins, cucumbers, yams, tapioca, chilies, beans, onion and arum are mostly cultivated. In fact, cutting across all states of Northeast India, the choice of crops among the shifting cultivators is mostly consumption oriented.

Shifting cultivation across the region has therefore, merged the cultural identities of the tribes who have been practising it since time immemorial. As a way of life, encompassing tradition and customs in cultivation with similar nature of crops being cultivated for self-sustenance contributing to food security, shifting cultivation has infact, cut across the barriers of diverse culture of those practising it in the region and have given them a common culture by dint of being Jhumias.

\section{Shifting Cultivation in Northeast India and the Divergent Views}

There are divergent opinions about the evil and adverse effects of shifting cultivation on the ecology and environment of Northeast India. A section of intellectuals believe that continuance of shifting cultivation with necessary and effective reforms can do little damage to soil erosion as high humidity and heavy rainfall in the region do not permit the soil to remain uncovered for long (Cherrieret all, 2018; Erni, 2015; UNFCCC, 2009; Priyadarshni, 1995). Some form of vegetation almost always covers the top soil which checks soil erosion. The shifting cultivation plots being almost steep slopes with little variations, and with no ploughing and hoeing of soil needed, jhum cultivation in the region over the centuries has evolved as a livelihood as a reflex to its topography but not without the knowledge of its adverse effects. Mostly, the shifting cultivation plots being abandoned for a suitable period, the land gets replenished naturally.

Yet, another section of intellectuals hold the view that jhum cultivation is primitive and depletes the forest, water and soil resources (Chauhan, 2001; Goel \& Krishnan, 2000; Husain et all, 1997; Ramakrishnan, 1993; Medhi, 1992; Maikhuri \& Ramakrishnan, 1991). Clearing of jungles is the prerequisite for shifting cultivation. Felling of trees and clearing of bushes accelerate soil erosion and accentuate variability of rainfall which may either lead to drought or flood. The overall impact is decline in soil fertility and the environment losing its resilience characteristics. The resultant is the shortage of food, fuel wood and fodder among the village households dependent on shifting cultivation thereby bringing in inconsistency in the nutritional standard of the households and ultimately leading to social poverty and ecological imbalance. It is held that since shifting cultivation damages the ecosystems, the practice of shifting cultivation needs to be discontinued. In general, as the cycle of shifting cultivation becomes shorter, it produces low yields of crops and has almost no potential beyond subsistence farming.

These divergent views on shifting cultivation practised in Northeast India has been a subject of debate and discussion for long. The recent National Institution of Transforming India (NITI Aayog) report of Government of India on shifting cultivation in Northeast India too tries amalgamating these divergent views and suggest the way forward (Tiwari \& Pant, 2018). The report infact, opens the door to further scientific, social, economic and cultural research into each aspect proposed. But even a futuristic probe into the different aspects proposed and their implementation thereafter, would call for reverence to this mode of production as an early human invention contributing to livelihoods and sustenance for generations now. While one school of modern economists and environmentalists continues viewing shifting cultivation as devastating to the ecosystem and therefore, disadvantageous exerting negative influences on the economy (Kalita et all, 2017), the other school continues to support shifting cultivation viewing that the practitioners of shifting cultivation are part of conservation (Das, 2006; Hazarika, 2017; Munda et all, 2010). What is perhaps needed is a more holistic understanding of the age-old practice as it continues to provide livelihoods across the region. Till then, the dilemma in Northeast India, therefore, continues 'with or without shifting cultivation'.

\section{Shifting Cultivation in Northeast India and a Look into New Measures Undertaken}

Of late, with adoption of modern technology and adjustments made with respect to intrusion of market economy, changing institutional arrangements from traditional institutions to private property regime, and changes in relative composition of food and commodity crops ranging from monoculture of cereals to monoculture of cash crops, Northeast India has witnessed some changes in the age-old methods and practice of shifting cultivation. Shifting cultivation in the region today can be identified as - (i) Traditional shifting cultivation, (ii) Distorted shifting cultivation, (iii) Innovative shifting cultivation, and (iv) Modified shifting cultivation (Tiwari, 2014).

Traditional shifting cultivation practices are still prevalent in the parts of the states like Meghalaya and Nagaland. The buffer zone of Nokrek Biosphere Reserve in Garo Hills in Meghalaya and Ngangching and Lazmi villages of Nagaland which have not experienced much population pressure continues with the traditional mode of shifting cultivation. It is also found that there is a high level of involvement of traditional village institutions across these villages in managing shifting cultivation. Traditional shifting cultivation practices with long fallow periods continue to aid in forest conservation. Infact, it has survived the test of time for thousands of years in the region, and has enabled the hill tribes to live in harmony 
with nature in the most hostile rugged environment often amidst dense moist evergreen forests teeming with wild life (Lianzela, 1997).

On the other hand, owing to teeming population in land scarce villages across states in the region, the tribal households are often forced to reduce the fallow period to accommodate newly built families through the institution of marriage. Across these villages, the fallow period is often reduced to one to three years, which is not enough for regeneration of the land. In many of these places like in parts of Arunachal Pradesh, Manipur hills and West Khasi Hills of Meghalaya, even if the fallow period has not been shortened, the jhum has spread to lands with steep slopes. This is due to the non-availability of lands with lesser degrees of slopes, which is neither productive nor sustainable. Distorted shifting cultivation, which abounds in the region, is therefore, an issue of concern.

Under innovative shifting cultivation, newer methods of cultivation through use of green biomass, technology and labour are being adopted. In some shifting cultivation pockets like Kolar Beans in Nagaland, Pisum in Pomlakarai, Meghalaya (Deb at all, 2013) and the Khasi and Karbi villages in Meghalaya, the system is found to have become more productive and market friendly by way of adopting new crops which help in maintaining soil and also has a good market. The shifting cultivators across the states in the region are constantly incorporating new measures to make shifting cultivation less destructive. Even the local traditional institutions have adopted some innovative measures like imposing fines for destruction of natural forests for carrying out shifting cultivation, fire control mechanisms, and conflict management and resolution with respect to shifting cultivation (Tiwari, 2014).

Shifting cultivation has several inherent mechanisms that make it a sustainable and relatively productive system of farming on the hill slopes. Some of the traditional innovative measures, such as crop diversity, weed management, retention of trees and soil conservation have the potentiality for implementation in modern agriculture systems in hilly regions. Even after the farmers have had exposure to modern agricultural tools and techniques, these innovative practices have helped in preserving the practice of traditional jhum cultivation. During the recent decades, Northeast India has seen some modifications in the process of shifting cultivation owing to implementation of two externally funded development projects - (i) Nagaland Environmental Protection and Economic Development (NEPED) in Nagaland, and (ii) North Eastern Regional Community Resource Management Project (NERCORMP) in Meghalaya, Manipur, and hill districts of Assam. These projects which were implemented in phases and ran for more than a decade were enshrined with major components to improve shifting cultivation.

However, many of the projects implemented in Northeast India have not had the kind of desired effects, and have tasted more hurdles than success. Reasons abound - (i) unilateral conceptualisation and formulation of schemes and reports with no dialogue and participation of the shifting cultivators, (ii) lack of well-founded research, (iii) dearth of integrated approach, (iv) want of intensive training to the implementing agencies as well as shifting cultivators, and (v) efforts lagging in sustained and intensive monitoring. Amidst it, for earning a livelihood, the Jhumias continue with the traditional mode of shifting cultivation.

\section{Sustainable Alternatives to Shifting Cultivation in Northeast India}

Assessing the fact that the jhum system cannot be stopped altogether, it is necessary to make the process more productive in order to accommodate and sustain the growing populace dependent on shifting cultivation. For a change in shifting cultivation typology, it is essential that the shifting cultivators or the Jhumias are provided with land they can cultivate and derive profits permanently (Darlong, 2004). One of the approaches may be to transform the shifting lands into sedentary farms. Another way may be, once the retrain ability of soil of the shifting cultivation fields is ensured, it can be augmented through the additional use of organic manures and fertilisers. However, the most common measure which has been adopted in many small tracts to accommodate the sedentary nature of farming across the hills of Northeast India is the development of terraces. Terraces of different types have come up in the region to fit in with a particular type of ecosystem. Infact, it is well accepted by now that terrace cultivation can be an efficient mode of production in hill areas. However, given the poor economic status of most of the shifting cultivators across Northeast India, cost involvement in terracing and regular supply of water to the terrace fields are the factors which need to be assessed. Having said this, however, it is the shifting cultivators in the region who have carved out terraces and bunding themselves, propagating awareness on expansion of protective covers on steep slopes with forests or fruit trees, grasses and leguminous crops, and cash crops. Therefore, diffusion of new crops with economic importance should be extended to the remote and isolated hill pockets of shifting cultivation of Northeast India. But, one has to go with the fact that it is the capacity and suitability of the land in question which needs to be taken into account for any land use planning in the region.

Concurrently, the shifting cultivators of Northeast India may also be imparted training in occupations outside the realm of shifting cultivation. Hands on training imparted in raising trees and orchards, indigenous handicrafts and handloom, and making them aware about the scope of coming up with micro enterprises in agriculture and allied sectors like dairy, piggery, goatery, poultry, sheep rearing, fisheries, beekeeping and floriculture would not only add to their household income but also open up vista of livelihood opportunities outside shifting cultivation. For effective implementation, business development service providers should work to provide need and opportunity based services including handholding in market access.

There is no denying the fact that shifting cultivation is a way of life in Northeast India with cogent reasons 
behind the customs and practices of the tribal people their climate, terrain, food habits, needs, and self-reliance, all have a say on shifting cultivation. The whole gamut of the tribal society is interwoven with the means of food production (Ramakrishnan, 1992). Moreover, where population densities are low, and given considerable time for replenishment of the soil, slash and burn practices may be sustainable and harmonious with the environment. The long run objective should be to have a socially accepted mode of production which does not disturb the ecosystem, maintaining at the same time ecological balance and economic feasibility. This calls for a number of measures which may be undertaken - (i) developing practical and relevant guidelines in policies that encourage farmers to adopt new sustainable variations in old modes of production, (ii) involvement and participation of the shifting cultivators in research and decision making with respect to shifting cultivation, (iii) consolidation of indigenous knowledge with modern scientific expertise, (iv) evaluation of policy options for recuperation of fallow land, (v) developing organic crop and pasture systems that aid in cycling nutrients to enhance soil fertility, and (vi) designing and organisation of biotic barriers to prevent soil erosion. To enhance the sustainability of the ecosystem, the steps may be considered as a package across shifting cultivation pockets in the region.

\section{Conclusion}

It is no doubt that shifting cultivation - the traditional farming system of Northeast India which has emerged over centuries of cultural and biological evolution represents the long standing experiences of the indigenous farmers interacting with the environment sans external support. In the mindset of the traditional shifting cultivators of Northeast India both forest and shifting cultivation practices are interlinked and intertwined. It might indeed be enigmatic to imagine that the basic philosophy of shifting cultivation has been to generate forests and not to extinguish them, for, without the existence of forest, the next jhum cycle cannot be nurtured (Darlong, 2004). On the other hand, one also needs to look into the fact that this practice clears the existing vegetation of the surrounding forest cover, an abode of many an exotic biological species. The forest can be regenerated after keeping them fallow for a while but the biological species cannot be retrieved back to the original habitat for which shifting cultivation practice has often been blamed for the biodiversity shrinkage in the region. While giving a relook into modifying this rich traditional practice in Northeast India, it is imperative to address issues like food and livelihood security, conservation of soil \& water, creating market linkages, and being in conformity with ecological principles. Transformation in any form should not only be an improvement upon the old older, rather must also accommodate the value system and needs of any society. In other words, this process of transformation itself should be comprehensive and socially, ecologically and economically sustainable.
Funding:

Not Applicable

Ethical approval for the research:

Not Applicable

No Conflict of Interest:

Not Applicable

Declaration on Ethical Conduct of Research:

I declare that this research has been conducted ethically.

\section{References}

AIPP \& IWGIA. (2014). Shifting cultivation, livelihood and food security new and old challenges for indigenous peoples in Asia. Published by Asia Indigenous Peoples' Pact (AIPP) and the International Work Group for Indigenous Affairs (IWGIA), Chiang Mai.

Chauhan, B. S. (2001). Shifting cultivation in Perspective. Nagaland University.

Borthakur, D. N. (1992). Agriculture of north eastern region. Guwahati:BeeCee Prakashan.

Chandel, S. (2017). Jhum cultivation: A critical analysis under Forest Act. Indian Agriculture. Retrieved from https://www.academia.edu/34880257/Jhum Cultivation_A_Critical_Analysis_Under_Forest_Act.

Cherrier, J., Maharjan, K, Maharjan, Keshav Lall. (2018). Shifting cultivation: misconception of the Asian. Journal of International Development and Cooperation, 24(1\&2), 71-82.

Christanty, L. (1986). Shifting cultivation and tropical soils: Patterns, problems and possible improvements. In Gerald G. Marten (Ed), Traditional Agriculture in Southeast Asia: A Human Ecology Perspective, Boulder, Westview Press, 226.

Darlong, V.T. (2004). To jhum or not to jhum policy perspective on shifting cultivation. The missing link (tml). Society for Environment and Communication, India, 143.

Das, D. (2006). Demystifying the myth of shifting cultivation: Agronomy in the north-east. Economic and Political Weekly, 41(47), 4912-4917.

Dollo, M. \& Sundriyal, R. C. (2003). Agricultural status and future potential in the state of Aruanchal Pradesh. Research Journal, Arunachal University, 6(2), 21-33.

Deb, S. \& Lynrah, M Mary \& Tiwari, B. (2013). Technological innovations in shifting agricultural practices by three tribal farming communities of Meghalaya, Northeast India. Tropical Ecology, May, 54(2), 133-148.

Erni, C. (2015). Shifting cultivation, livelihood and food security, new and old challenges for indigenous peoples in Asia. Food and Agriculture Organization of the United Nations \& International Work Group for Indigenous Affairs and Asia Indigenous Peoples 
Pact Bangkok.

Goel, N. P, Krishnan, G. (2000). Geography of Northeast India. Shillong Book Stall, Bara Bazar, Shillong

Hazarika, S. (2017). Options for natural resource conservation for jhum improvement in Neh region. In N. Prakash and et all (Eds), Jhum Improvement for Sustaining Farm, Livelihood and Natural Resource Conservation in North Eastern Hill Region: Vistas and Frontiers, Director, ICAR Research Complex for NEH(North Eastern Hill Region) Region.

Husain, M. (1995). Systematic agricultural geography. Rawat Publications,

Husain M, Zaidi, H S. S. (1996). Environmental management in India. Manas Publications Pvt.Ltd.

Kalita, H. Baruah, M. S., Datta, D., Jini, D. \& Alone, R. A. (2017). Status of shifting cultivation (jhum) in Arunachal Pradesh, India. In N. Prakash and et all (Eds), Jhum Improvement for Sustaining Farm, Livelihood and Natural Resource Conservation in North Eastern Hill Region: Vistas and Frontiers, Director, ICAR Research Complex for NEH Region.

Kerkhoff, E. and Sharma, E. (2006). Debating shifting cultivation in the eastern himalayas. Farmers innovations as lessons for policy. International Centre for Integrated Mountain Development.

Lianzela. (1997). Effects of shifting cultivation on the environment: With special reference to Mizoram. International Journal of Social Economics, 24(7/8/9), 785-790.

Maikhuri, R. K. and Ramakrishnan, P. S. (1991). Comparative analysis of the village ecosystem function of different tribes living in the same area in Arunachal Pradesh living in north-eastern India. Agricultural Systems, 9, 57-72.

Medhi, R. (1992). Global warming and its implications for the development world. Rawat Publication.

Munda, G. C., Ngachan, S. V., Das, A., Satapaty K.K., Biswas, S and Malngiang, S. (2010). Livelihood improvement through farming systems and subsidiary activities in disadvantaged districts of North East India. NAIP Bulletin, 1.

Priyadarshni. (1995). Shifting cultivation: cropping patterns, jhum cycle and problems. Accessed on January 6, 2019 at http://www.yourarticlelibrary. $\mathrm{com} /$ cultivation/shifting-cultivation-croppingpatterns-jhum-cycle-and-problems/44650.

Ramakrishnan, P.S. (1992). Shifting agriculture and sustainable development: an interdisciplinary study for North-Eastern India. Man and Biosphere Series, Book 10, UNESCO and Parthenon Publishing.

Siddiqui, S \& Chohan, S. (2015). Legal response to institutionalising participatory land use planning in nagaland: developing strategies for mainstreaming sustainable jhum practices into existing policy and legal framework of nagaland. UNDP Report, The Printing Wala.

Tiwari, B. K. (2014). Policies and alternative options to
Shifting cultivation in northeast India - a review 2004-2014. NEHU

Tiwari, B.K.\& Pant, R.M. (2018). Shifting cultivation: towards transformation approach. A draft report prepared by the thematic working group on shifting cultivation: towards a transformation approach, NIRDPR, NERC.

Tripathi, R. S. and Barik, S. K. (2003). Shifting cultivation in North East India. In B P Bhat, K M Bujarbaruah, Y P Sharma and Patiram (Eds), Approaches for Increasing Agricultural Productivity in Hill and Mountain Ecosystem, ICAR.

UNFCCC. (2009). Shifting cultivation and climate change. UNFCCC Inter sessional Meeting, Bangkok, Briefing Paper.

Ratna Bhuyan, PhD, (http://orcid.org/0000-00020494-5429), is a Social Scientist. She has earned PhD in Economics from the Gauhati University, Guwahati, Assam, India. Bhuyan is currently working at the National Institute of Rural Development and Panchayati Raj, an autonomous organisation under Ministry of Rural Development, Government of India. Her research focuses on promotion of rural and traditional livelihoods, promotion of nano and micro-enterprise clusters across the Northeastern region of India. Other areas of interest include reviewing policies and projects related to socio-economic development, peace research, skill development and research methods in social science. She has co-authored and co-edited a few books and has published papers in peer-reviewed journals. She has also been the copy editor for publications under different publication houses including Oxford publications.

Email: ratnabhuyan.nird@gov.in, bhuyanmamu@gmail.com 